
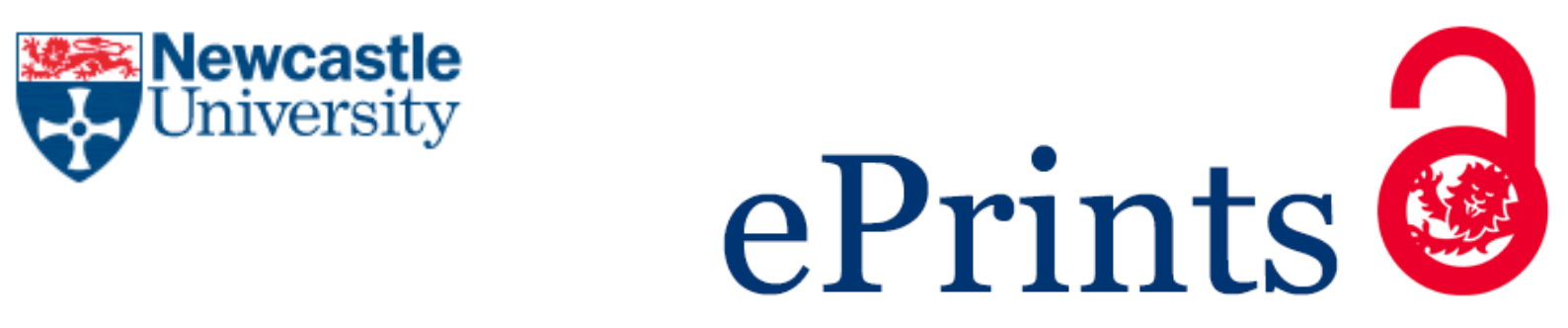

Bhat T, Kandare E, Gibson AG, Modica PD, Mouritz AP.

Compressive softening and failure of basalt fibre composites in fire:

Modelling and experimentation.

Composite Structures 2017, 165, 15-24

Copyright:

(C) 2017. This manuscript version is made available under the CC-BY-NC-ND 4.0 license

DOI link to article:

http://dx.doi.org/10.1016/j.compstruct.2017.01.003

Date deposited:

$25 / 01 / 2017$

Embargo release date:

04 January 2018

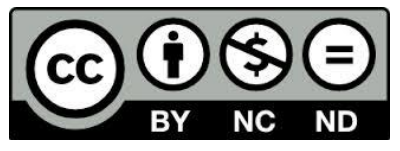

This work is licensed under a

Creative Commons Attribution-NonCommercial-NoDerivatives 4.0 International licence 


\title{
COMPRESSIVE SOFTENING AND FAILURE OF BASALT FIBRE COMPOSITES IN FIRE: MODELLING AND EXPERIMENTATION
}

\author{
T. Bhat ${ }^{1}$, E. Kandare ${ }^{1}$, A.G. Gibson ${ }^{2}$, P. Di Modica ${ }^{2}$, A.P. Mouritz ${ }^{1}$ \\ ${ }^{1}$ Sir Lawrence Wackett Aerospace Research Centre, School of Engineering, RMIT University, Melbourne, \\ Victoria 3000, Australia \\ ${ }^{2}$ Centre for Composite Materials and Engineering, University of Newcastle-upon-Tyne NE1 7RU, UK \\ Corresponding author: \\ Adrian P. Mouritz \\ Tel: +61399256269 \\ Fax: +61 399256108 \\ e-mail: adrian.mouritz@rmit.edu.au
}

\begin{abstract}
In this study, the fire structural properties of a basalt fibre reinforced polymer laminate under compressive loading was investigated analytically and experimentally, and compared against an E-glass fibre composite with the same fibre content, ply orientation and polymer matrix. A thermal-mechanical model was used to compute the softening rate and failure stress of basalt fibre laminates which collapse, when loaded in compression, by either global buckling or compressive failure when exposed to fire. Fire structural measurements involving one-sided radiant heating with axial compressive loading were also performed. The measurements revealed, surprisingly, that the softening behaviour and failure stress of the basalt fibre laminate were inferior to those of the glass fibre composite. Furthermore, the fire reaction properties, such as heat release rate and smoke density, were also less favourable for the basalt laminate. This appears to be mainly due to the thermal absorptivity of the basalt fibre laminate being higher, which causes it to heat up at a faster rate and reach higher temperatures when exposed to a radiant heat flux.
\end{abstract}

Keywords: Polymer matrix composites; thermomechanical behaviour; basalt fibre; fire. 


\section{$1 \quad$ INTRODUCTION}

Basalt fibre composites [1-5] are being considered, in competition with glass fibre, for use in automotive components, civil infrastructure, and other applications, due to an attractive combination of properties. These are claimed to include excellent durability and somewhat improved mechanical properties for a modest cost premium. However, there is currently some confusion regarding the relative merits of the two fibre types, due to differences in information from varied sources.

Depending on the source and composition of the basalt rock, basalt fibre has been reported to possess similar or higher tensile stiffness and strength compared to E-glass fibre [1-5]. Basalt fibre is claimed to possess excellent heat insulation properties, with similar thermal conductivity and specific heat capacity to E-glass. For these reasons, basalt fibre is a potential substitute to E-glass fibre for the reinforcement of polymer matrix composites.

The ambient temperature mechanical properties of basalt fibres [6-10] and their composites $[1,2,4]$ have been widely reported, although much less is known about their elevated temperature and fire structural properties. Fire response is a key weakness for most composites due to the evolution of heat, smoke and toxic fumes from the polymer matrix. Structural weakening is also a serious hazard, especially in compressive loading, as composites soften, deform and collapse when exposed to fire. The fire structural properties of glass and carbon fibre composites have been investigated and modelled [11-24]. However there is relatively little equivalent information in the literature about basalt fibre laminates.

Bhat et al. [25] recently characterised the fire resistance of a basalt fibre laminate subjected to tensile loading, and discovered, surprisingly, that its performance was inferior to an E-glass 
composite. This work showed that basalt and E-glass fibre tows within composite materials soften at very similar rates over a similar range of temperatures, with most weakening occurring between $\sim 250^{\circ} \mathrm{C}$ and $550^{\circ} \mathrm{C}$. However, the basalt fibre laminate was shown to have inferior fire structural resistance under tensile loading because it heated up more rapidly than the glass fibre composite when exposed to fire. Apart from that study, the fire structural properties of basalt fibre composites have not been widely reported, despite their potential use in many applications where fire poses a risk.

The present study evaluates the potential impact of replacing E-glass fibres with basalt fibres on the fire structural properties of polymer composites in compression. Compressive loading is especially important when considering the performance of structural columns, wall panel assemblies and other types of load-bearing components exposed to fire. The fire resistant properties of a basalt fibre laminate are experimentally characterised and modelled in the present paper, and compared to an E-glass composite with the same fibre content, ply orientation and polymer matrix. The composites are compared using fire structural tests involving combined axial compression loading and one-sided heating at a constant thermal flux. The softening rate, deformation behaviour and compressive load-bearing performance of the basalt and glass fibre laminates are compared here for two heat flux conditions representative of moderate (radiant temperature of $470^{\circ} \mathrm{C}$ ) and medium intensity $\left(640^{\circ} \mathrm{C}\right)$ fires. In addition, the fire reaction properties of the laminates are compared, including heat release rate and smoke density, to further assess whether substituting E-glass with basalt in composites poses an increased fire safety risk.

\section{MATERIALS AND EXPERIMENTAL METHODOLOGY}

\subsection{Composite Materials}


The basalt fibre laminate was prepared using a plain woven basalt fabric containing 300 tex tows and having an areal density of $350 \mathrm{~g} / \mathrm{m}^{2}$ (Zhejiang GBF Fiber Co. Ltd.). The basalt fabric stacked in a cross-ply tow pattern with the warp tows in each ply aligned in the same direction. The fabric preform was then infused at room temperature with vinyl ester resin (SPV1349 Nuplex Composites) using the vacuum bag resin infusion (VBRI) process. Following infusion, the laminate was cured in ambient conditions $\left(23^{\circ} \mathrm{C}, 55 \% \mathrm{RH}\right)$ for 24 hours and then post-cured at $80^{\circ} \mathrm{C}$ for 2 hours. The basalt fibre volume content was measured to be $51 \pm 2 \%$ using the ASTM D-3171 burn-off technique.

The fire structural properties of the basalt laminate were compared against a near-equivalent glass fibre composite. This composite was made with plain woven E-glass fabric $\left(830 \mathrm{~g} / \mathrm{m}^{2}\right)$ containing 300 tex tows (Colan Australia). The glass fabric was stacked in the same cross-ply fibre pattern as the basalt fabric to ensure both composites had the same fibre orientations. The glass fabric was infused using the VBRI process with the same vinyl ester resin and cured under the same conditions as the basalt fibre laminate, making the manufacturing process and the polymer matrix the same in both composite laminates. The volume content of glass fibres in the composite was $55 \pm 3 \%$, which was only slightly higher ( 4 vol\%) than the basalt fibre laminate. The glass transition temperature $\left(T_{g}\right)$ of the two laminates was measured using DMTA to be $120^{\circ} \mathrm{C}$, as defined by a $50 \%$ reduction in the storage modulus from the room temperature value.

Table 1 gives the mechanical properties of the basalt and glass fibres and their composites measured at $20^{\circ} \mathrm{C}$. The compressive failure stress of the basalt fibre laminate was lower (198 $\mathrm{MPa})$ than the E-glass composite (255 MPa). The lower strength may be due to several factors, including the slightly lower fibre volume content and the higher crimp (waviness) in 
the woven basalt tows, which lowers the compressive stress required to initiate failure via tow kinking.

\section{2 $\quad$ Fire Structural Testing}

Fire structural compression experiments were performed on the basalt and E-glass laminates using identical test conditions to compare their fire resistant properties. The test involved subjecting the laminates to simultaneous axial compression loading and one-sided heating at a constant thermal flux, as shown schematically in Figure 1. The laminate samples were flat rectangular beams measuring $600 \mathrm{~mm}$ long, $50 \mathrm{~mm}$ wide and $9 \mathrm{~mm}$ thick. Testing involved compressing the laminate samples along their length (which was the warp $\left(0^{\circ}\right)$ tow direction) at a constant stress between $20 \%$ and $80 \%$ of the Euler buckling stress at room temperature, which was $21 \mathrm{MPa}$ for both the basalt and glass laminates.

While under constant stress, a $100 \mathrm{~mm}$ long middle section of the laminate sample was exposed to a constant heat flux of 25 or $50 \mathrm{~kW} / \mathrm{m}^{2}$ radiated from a $5000 \mathrm{~W}$ circular heater (150 mm diameter). The thermal flux was calibrated before testing using a heat flux gauge (Medtherm, Model: 32-10SB-10-197-21633). The temperature of the heater at the thermal fluxes of 25 and $50 \mathrm{~kW} / \mathrm{m}^{2}$ was $470^{\circ} \mathrm{C}$ and $640^{\circ} \mathrm{C}$, respectively. The heater was located 25 $\mathrm{mm}$ from the front surface of the laminate sample, and both were oriented in the vertical direction. Only the central region of the laminate region was exposed to the heat flux (as indicated in Fig. 1), while the other regions were thermally insulated to avoid softening and heat damage. The in-plane extension and contraction of the laminate samples was recorded continuously during testing from the cross-head displacement of the loading machine, which was a $250 \mathrm{kN}$ MTS fitted with the smoke and fume extraction system. The out-of-plane deflections of the samples were measured using a linear variable differential transformer 
(LVDT) attached to the back surface. Testing was continued until the sample failed, which was defined by the inability of the laminate to carry the applied compressive load.

\subsection{Fire Reaction Testing}

The fire reaction properties of the basalt and glass fibre laminates were measured using a three-cell cone calorimeter (Fire Testing Technology Ltd, Model: 5023431) operated in the vertical testing mode. The properties measured were heat release rate, mass loss and smoke density. The laminate samples $(100 \mathrm{~mm}$ long $\times 100 \mathrm{~mm}$ wide $\times 9 \mathrm{~mm}$ thick $)$ were exposed to a constant incident thermal flux of 25 or $50 \mathrm{~kW} / \mathrm{m}^{2}$ (without a spark ignitor) according to ISO 5660 [26]. The heat-exposed surface of the sample was positioned $25 \mathrm{~mm}$ from the cone heater, which was the same type used to radiate the heat flux in the fire structural test. The heating conditions used to measure the fire reaction properties using the cone calorimeter were identical to the conditions experienced by the laminates during the fire structural test.

\subsection{X-ray Computed Tomography}

$\mathrm{X}$-ray computed micro-tomography $(\mathrm{X}$-ray $\mu-\mathrm{CT})$ was performed on the glass following fire testing using a General Electric (phoenix v|tome|x s) instrument. A 360 3-D multi-scan was performed using a X-ray micro-tube operated at $100 \mathrm{kV}$ and $200 \mu \mathrm{A} .1000$ image projections were recorded per sample at $200 \mathrm{~ms}$ intervals and voxel size of $48 \mu \mathrm{m}$ to obtain high resolution images of the composites.

\section{FIRE STRUCTURAL MODELLING}

A thermo-mechanical model was used to analyse the temperature, decomposition, thermal softening and compressive failure stress of the basalt and E-glass laminates exposed to a constant heat flux. The model involves a two-step approach: (i) one-dimensional thermal 
analysis to compute the through-thickness temperatures of the laminates with increasing exposure time to the heat flux and (ii) mechanical analysis to calculate the reduction in compressive strength caused by thermal softening. With the thermal analysis, the model does not analyse the fire environment itself, although this can be done using computational fluid mechanics [27]. With the mechanical analysis, the model assumes that the laminate collapses under compressive loading via global (Euler) buckling or material failure.

\subsection{Thermal Model}

A model developed by Henderson et al. [28] was used to calculate the temperature of the laminates when exposed to a constant heat flux. The one-dimensional governing equation for calculating the temperature at any location in the through-thickness direction of the laminate is expressed as:

$\rho(T) C_{p}(T) \frac{\partial T}{\partial t}=\frac{\partial}{\partial x}\left(k(T) \frac{\partial T}{\partial x}\right)-\left(Q+h_{C}-h_{G}\right) \frac{\partial \rho}{\partial t}-\dot{m}_{G} C_{G} \frac{\partial T}{\partial t}$

The terms to the right hand side of Eq. (1) relate to the key processes controlling the temperature of the laminate: heat conduction, decomposition of the polymer matrix, and volatile convection, respectively. The first term accounts for the heat conduction from the heated surface through-the-thickness of the laminate to the back surface. The second term accounts for decomposition of the polymer matrix, which is a negative term because for the polymer used here (vinyl ester) the reaction process is endothermic. The third term accounts for the convective cooling effect caused by hot gases when they diffuse from the decomposition zone in the laminate to the heated surface.

In Eq. (1), $T, t$ and $x$ define the temperature, heating time and distance below the heated laminate surface, respectively. $\rho$ is the instantaneous density of the laminate, which decreases 
as the polymer matrix decomposes into char and volatiles. $M_{g}$ is the mass flux of volatiles flowing through the laminate towards the heated surface. $h_{c}$ and $h_{g}$ are the enthalpies of the laminate and volatiles, respectively. $Q$ is the endothermic decomposition energy of the polymer matrix. $C_{p}$ and $k$ are the specific heat and thermal conductivity of the laminate, respectively.

The polymer matrix is assumed to decompose via a single-stage endothermic reaction process which can be defined by the Arrhenius rate equation:

$$
\left[\frac{\partial \rho}{\partial t}\right]=-\left(\rho_{v}-\rho_{\text {char }}\right)\left[\frac{\rho-\rho_{\text {char }}}{\rho_{v}-\rho_{\text {char }}}\right]^{n} \cdot A e^{-Q / R T}
$$

The order of reaction, $n$, is assigned a value of unity in this study. The kinetic (Arrhenius) parameters $(A$ and $Q)$ for the vinyl ester matrix were determined using thermogravimetric analysis (TGA), and the values are given in Table 2.

The unheated surface of the laminate is assumed to be fully-insulated and have the thermal boundary condition defined by:

$$
-\left.k_{x} \frac{\partial T}{\partial x}\right|_{x=t_{C}}=0
$$

where $t_{c}$ is the thickness.

\subsection{Mechanical Model}

Two models are used to calculate the compressive softening and failure of laminates exposed to one-sided heating by fire. These models are called the 'average strength model' and 'buckling model'. 


\subsubsection{Average Strength Model}

The average strength model was developed by Feih et. al. [18] to calculate the compressive failure stress of fibreglass laminates exposed to fire. The model assumes that the compressive strength at any location in the through-thickness direction of the laminate is dependent upon the temperatures at these locations. The local temperatures are calculated using Eqn. 1 with increasing increments of time.

The local compressive failure stress at any point in the laminate material can be calculated from the local temperature at the same point using the semi-empirical equation [17]:

$\sigma_{c}(T)=\left(\frac{\sigma_{c(o)}+\sigma_{c(R)}}{2}-\frac{\sigma_{c(o)}-\sigma_{c(R)}}{2} \tanh \left(\varnothing\left(T-T_{k}\right)\right)\right) \times R_{r c}(T)^{\alpha}$

$\sigma_{c(o)}$ and $\sigma_{c(R)}$ are the failure stress values of the laminate at room temperature and in the fully softened condition, respectively. In this work, fully softening is defined by the minimum compressive strength of the laminate when the polymer matrix has reached a steady-state relaxation due to glass transition softening. $T_{k}$ is the mechanical glass transition temperature, which is defined as the temperature at which the composite loses $50 \%$ of its room temperature compressive strength. $\emptyset$ is a material constant defining the temperature range over which the compressive strength is reduced by glass transition softening. $R_{r c}(T)$ is a scaling function to account for mass loss due to decomposition of the polymer matrix and the exponent ' $\alpha$ ' is an empirical value, which is set to 3 based on previous research [18].

The values for $\sigma_{c(R),} T_{k}$ and $\emptyset$ must be measured experimentally by performing compressive strength tests on the laminate within the temperature range over which glass transition softening occurs. Therefore, short block compression tests were performed on the basalt and glass laminates at temperatures between $20^{\circ} \mathrm{C}$ and $200^{\circ} \mathrm{C}$. The short block specimens were 50 
$\mathrm{mm}$ long, $25 \mathrm{~mm}$ wide and $4 \mathrm{~mm}$ thick, with an unsupported gauge length of $25 \mathrm{~mm}$. The specimens were axially loaded in the warp fibre direction at an end shortening rate of 1 $\mathrm{mm} / \mathrm{min}$ under isothermal conditions inside a hot box attached to a $50 \mathrm{kN}$ Instron Machine (Model no: 55690). As shown in Figure 2, the compressive failure stress and elastic modulus of both laminates decreased with increasing temperature due to glass transition softening of the polymer matrix. The failure stress reached a minimum value above $\sim 150^{\circ} \mathrm{C}$ (Fig. 2a). The curves shown in Figure 2a were calculated using Eqn 4, from which the values for $\sigma_{c(R)}$, $T_{k}$ and $\emptyset$ for the two laminates were determined and are given in Table 3 .

The failure stress of the laminate exposed to fire is computed by determining the local strength values at a number of locations in the through-thickness direction (Eqn. 4), which is based on the local temperatures (Eqn 1). The local material strength values are then averaged (or smeared) over the load-bearing area of the laminate using Simpson integration:

$\sigma_{a v}=\frac{1}{h} \int_{-x / 2}^{+x / 2} \sigma\left(T_{a v}(x), t_{e f f}(x)\right) d x$ with:

$\int_{-x / 2}^{+x / 2} \sigma\left(T(x), t_{e f f}(x)\right) d x=\frac{h}{3 m}\left[\sigma\left(T_{a v}\left(x_{0}\right), t_{c}\left(x_{0}\right)\right)+4 \sigma\left(T\left(x_{1}\right), t_{c}\left(x_{1}\right)\right)+2 \sigma\left(T\left(x_{2}\right), t_{c}\left(x_{2}\right)\right)+\right.$ $\left.\cdots+2 \sigma\left(T\left(x_{k-2}\right), t_{c}\left(x_{k-2}\right)\right)+4 \sigma\left(T\left(x_{k-1}\right), t_{c}\left(x_{k-1}\right)\right)+\sigma\left(T\left(x_{k}\right), t_{c}\left(x_{k}\right)\right)\right]$

$m$ defines the number of locations in the through-thickness direction where the local material failure stress is calculated. $h$ is the laminate thickness. Failure is assumed to occur when the bulk material failure stress of the laminate decreases to the same value as the applied compressive stress.

\subsubsection{Buckling Model}

This model analyses the compressive failure by global buckling of a long, slender beam of the laminate exposed to fire. The buckling stress is simply determined using the Euler buckling equation for a flat, straight-sided long beam with simply supported constraints: 
$P_{b u}=\frac{\pi^{2}}{L^{2}} E_{c}(T) I$

where $P_{b u}$ is the buckling load, $L$ is the unsupported beam length, and $I$ is the moment of inertia of the beam. $E_{c}$ is the axial compressive modulus of the laminate, which is dependent on the temperature. The in-plane modulus of the laminate in the through-thickness direction can be calculated from the local temperature using:

$E_{c}(T)=\left(\frac{E_{c(o)}+E_{c(R)}}{2}-\frac{E_{c(o)}-E_{c(R)}}{2} \tanh \left(\emptyset_{b}\left(T-T_{k}\right)\right)\right) \times R_{r c}(T)^{n}$

$E_{c(o)}$ and $E_{c(R)}$ are the modulus values of the laminate at room temperature and in the fully softened condition, respectively. $\emptyset_{b}$ is a material constant describing the temperature range over which the compressive modulus is reduced by glass transition softening. $E_{c(o),} E_{c(R)}$ and $\emptyset_{b}$ are determined from compression tests performed on the laminate over a wide range of softening temperatures. Figure $2 b$ shows the effect of increasing temperature on the compression modulus of the basalt and glass fibre laminates, and the curves were computed using Eqn 7. ). It was not possible to reliability measure the modulus above $150^{\circ} \mathrm{C}$ using an extensometer, and so higher temperature data is not provided. The curve fit values for $E_{c(o) \text {, }}$ $E_{c(R)}$ and $\emptyset_{b}$ are given in Table 3 .

The bulk compression modulus $\left(E_{c}\right)$ of the laminate is obtained by integrating the local modulus values calculated using Eqn 7 over the load-bearing area of the laminate exposed to fire using: .

$$
\begin{aligned}
& E_{c}=\frac{1}{h} \int_{-x / 2}^{+x / 2} E\left(T_{a v}(x), t_{e f f}(x)\right) d x \text { with: } \\
& \int_{-x / 2}^{+x / 2} E\left(T(x), t_{e f f}(x)\right) d x=\frac{h}{3 m}\left[E\left(T_{a v}\left(x_{0}\right), t_{c}\left(x_{0}\right)\right)+4 E\left(T\left(x_{1}\right), t_{c}\left(x_{1}\right)\right)+\right. \\
& 2 E\left(T\left(x_{2}\right), t_{c}\left(x_{2}\right)\right)+\cdots+2 E\left(T\left(x_{k-2}\right), t_{c}\left(x_{k-2}\right)\right)+4 E\left(T\left(x_{k-1}\right), t_{c}\left(x_{k-1}\right)\right)+ \\
& \left.E\left(T\left(x_{k}\right), t_{c}\left(x_{k}\right)\right)\right]
\end{aligned}
$$


Failure is assumed to occur when the decreasing bulk modulus of the laminate degrades the buckling stress (calculated using Eqn. 6) to the same value as the applied compressive stress.

\section{RESULTS AND DISCUSSION}

\subsection{Thermal Response of Basalt Fibre Laminates}

Temperature-heat flux exposure time curves for the basalt and glass laminates when exposed to the low $\left(25 \mathrm{~kW} / \mathrm{m}^{2}\right)$ and high $\left(50 \mathrm{~kW} / \mathrm{m}^{2}\right)$ thermal fluxes are shown in Figures 3 and 4 , respectively. The dotted lines show the experimental temperatures measured using thermocouples attached to the front (heat-exposed) surface, middle and back surface of the laminates. Multiple tests performed on laminates revealed little variability in the measured temperatures (typically within $15^{\circ} \mathrm{C}$ ). Both laminates experienced an initial rapid rise to the front face temperature, although the basalt composite experienced a much faster heating rate and reached higher temperatures than the glass composite when both materials were exposed to the same heat flux. The middle and back surface temperatures of the basalt laminate also increased at a faster rate and reached higher values. This suggests that substituting glass with basalt fibres in composite structures will result in higher surface and internal temperatures when exposed to heat radiated by fire. The thermal conductivity $(k)$ and specific heat capacity $\left(C_{p}\right)$ values for basalt fibre $\left(k=0.031-0.038 \mathrm{~W} / \mathrm{m} . \mathrm{K} ; C_{p}=860 \mathrm{~J} / \mathrm{kg} . \mathrm{K}\right)$ and E-glass fibre $(k=$ 0.034-0.040 W/m.K; $\left.C_{p}=840 \mathrm{~J} / \mathrm{kg} . \mathrm{K}\right)$ are nearly identical, which implies the temperaturetime profiles of the two laminates when exposed to the same heat flux should be similar. Therefore, the higher measured temperatures of the basalt laminate shown in Figures 3 and 4 cannot be due to more rapid heat transfer from the heated surface. Instead, the faster heat-up rates and higher temperatures were due to the higher absorptivity coefficient of the basalt laminate. The absorptivity coefficient of the basalt laminate $(\varepsilon=0.92)$ was measured at room temperature using an infrared camera to be much higher than the glass composite $(\varepsilon=0.65)$. 
As a result, the basalt laminate absorbed more thermal energy at the heated surface which accelerated the heating rate and thereby increased the internal and back surface temperatures. These results suggest that basalt laminates pose a potentially greater fire hazard because they absorb more heat within a shorter time than glass composites.

The solid lines shown in Figures 3 and 4 were calculated using the thermal model described in Section 3.1 and using the thermal and other property data given in Table 2. There is good agreement between the calculated and measured temperatures for the glass laminate. Other studies have previously shown that the model can accurately compute the temperature of fibreglass laminates [17-20,28]. The thermal model also accurately calculated the temperatures for the basalt laminate at the lower heat flux, but not at the higher flux because the material ignited within the short time. Ignition occurs when the mass flux of flammable volatiles released via decomposition of the polymer matrix reaches a critical concentration at the composite/fire interface. The thermal model developed by Henderson et al. [28] cannot accurately compute the temperature of composite materials after they ignite and start burning.

\subsection{Fire Reaction Properties of Basalt Fibre Laminates}

Fire reaction properties such as heat release rate (HRR), peak heat release rate (HRR) and smoke specific extinction area (SEA) are often used to evaluate the fire safety hazard of combustible materials, including composites [21,29]. HRR is considered the most important fire reaction property because it quantifies the amount of heat released by a thermally decomposing material which then adds to the thermal load of a fire. The effect of increasing exposure time to the low and high heat flux on the heat release rates of the laminates is shown in Figure 5. When exposed to the low heat flux, the HRR value of the glass fibre laminate remained relatively low and constant. Little heat was generated because the maximum 
temperature reached by the laminate $\left(\sim 400^{\circ} \mathrm{C}\right)$ was just above the temperature at which the vinyl ester matrix starts to decompose $\left(\sim 350^{\circ} \mathrm{C}\right)$ [17]. In contrast, the HRR of the basalt laminate increased steadily with time when exposed to the low heat flux. This occurred despite the volume content and type of polymer matrix in both laminates being the same. However, due to the higher absorptivity of the basalt laminate it heated up more rapidly and reached higher temperatures, and this caused the matrix to decompose faster and to a greater extent than the glass composite. The outgassing of hot volatiles generated by the decomposition reaction process thereby increased the HRR of the basalt laminate. The difference in the HRR properties of the two laminates is more apparent at the higher heat flux (Fig. 5b), which shows that the basalt laminate released heat sooner and to much higher values than the glass composite.

The mass loss to the basalt laminate when exposed to the heat flux was also greater than the glass composite, as shown in Figure 6. The mass loss was caused by decomposition of the polymer matrix generating volatiles (mostly low molecular hydrocarbons, $\mathrm{CO}, \mathrm{CO}_{2}$ ) which diffused out of the laminate. The basalt laminate began to lose mass sooner and to a greater weight percentage, and this was again due to the faster heating rate and higher temperatures caused by the high absorptivity. Due to the faster decomposition rate, the amount of smoke generated by the basalt laminate was also higher, as shown in Figure 7.

Table 4 compares the fire reaction properties of the laminates when exposed to the low and high heat flux, and in many cases these are worse for the basalt fibre laminate indicating a greater fire hazard because it released more heat and smoke than the glass composite. 


\subsection{Compressive Deformation and Failure of Basalt Laminates in Fire}

The deformation response of polymer laminate beams under simultaneous compression loading and one-sided exposure to fire is controlled by mechanical and thermal loads which induce axial displacements and lateral deflections, as shown schematically in Figure 8 [30]. Examples are shown in Figure 9 for the axial (in-plane) extension and Figure 10 for the lateral (out-of-plane) deflections experienced by the basalt and glass laminates when exposed to the heat flux for increasing times up to failure. The curves show the typical effect of increasing exposure time to the high heat flux $\left(50 \mathrm{~kW} / \mathrm{m}^{2}\right)$ on the deformation responses of the laminates when loaded at low (20\% of the room temperature buckling load) and high (80\%) compressive forces. During the initial heating period the laminates expanded despite being under a compressive force, and this was due to the thermal expansion effect. The axial extension-time curves shown in Figure 9 reached a peak value following which the laminates began to axially contract prior to failure. Concurrently, the laminates deflected laterally towards and then away from the heat source, as shown in Figure 10, and this was due to a thermal moment created by the steep through-thickness temperature gradient. When exposed to one-sided heating, greater thermal expansion strain is developed at the heat exposed surface and therefore the laminate bends toward the heat source. Once the heat-exposed surface exceeds the glass transition temperature of the matrix then the laminate softens and deflects away from the heat source. The steep thermal gradient in the through-thickness direction of the laminate causes a non-uniform reduction in the compression stiffness; the elastic modulus near the heated surface (above $\mathrm{T}_{\mathrm{g}}$ ) is much lower than the cooler back surface (below $\mathrm{T}_{\mathrm{g}}$ ). With increasing time, this shifts the neutral axis away from the centroid closer to the back surface of the laminate, thereby causing it to laterally bend away from the heat source. The lateral deflections of the basalt laminate occurred more rapidly and to a greater extent than the glass composite due to a higher thermal moment. The moment was higher 
because the heating rate of the basalt laminate was greater due to the higher absorptivity which induced a steeper through-thickness thermal gradient.

The effect of the applied compressive stress on the failure times of the basalt and glass laminates exposed to the low and high heat flux are shown in Figures 11 and 12, respectively. Failure time is defined as the exposure time to the heat flux needed to cause the laminate to collapse under the applied stress. The failure times for both laminates increased when the compressive stress was reduced, although failure occurred sooner for the basalt composite which is indicative of inferior fire structural resistance under compression. The failure times were also longer when the heat flux was reduced, and again basalt laminate failed earlier than the glass composite. The fire structural performance of the basalt laminate was inferior due to its higher absorptivity, which accelerated the heating rate and thereby caused it to soften at an increased rate leading to failure.

The failure modes of both the basalt and glass laminates were the same, despite the basalt composite failing earlier. Two competing failure modes occurred: failure occurred via global buckling of the laminate specimen or by material failure involving plastic kinking (microbuckling) of the load-bearing tows. Buckling occurred when the applied compressive stress was high, and involved the laminate deflecting laterally due to the thermal moment and then buckling due to weakening caused by glass transition softening of the polymer matrix near the heated surface. The high lateral deflection of the laminate caused the load-bearing tows to rupture, as shown by the cross-sectional X-ray computed tomography image in Figure 13a. When the applied stress was relatively low, the laminate failed by plastic kinking of the tows rather than global buckling, as shown in Figure 13b. Plastic kinking occurred because the shear modulus of the thermally softened polymer matrix was low, and this lowered the 
critical compressive stress needed for the tows to rotate through a large angle from the load direction leading to material failure.

The curves in Figures 11 and 12 show the calculated effect of the applied stress on the failure times using the buckling and average strength models. The property data used to solve the models is provided in Table 3. The two models predict the trends showing that the failure time increases with decreasing stress and/or heat flux. Both models also predict the failure times for the basalt laminate are shorter than the glass composite. The buckling model predicts shorter failure times than the average strength model at relatively high applied stress levels (above $\sim 10 \mathrm{MPa}$ ), whereas at lower stresses longer failure times are calculated. As mentioned, failure of the laminates involved two competing mechanisms: global buckling at high stresses and plastic kinking at low stresses. The solid curve (labelled 'combined model') in Figures 11 and 12 show the calculated failure times by combining the predictions of the buckling and average strength models. Failure is assumed to occur by buckling when the failure times calculated using the buckling model are shorter than those predicted with the average strength. Similarly, it is assumed failure occurs by plastic tow kinking when the average strength model predicts shorter failure times than the buckling model. The solid curves show good agreement with the measured failure times. The model also explains the reason for the two competing failure mechanisms, with global buckling and material failure predicted at high and low stress levels respectively.

\section{CONCLUSIONS}

This study has demonstrated that the replacement of glass fibre by basalt fibres in structural composites can significantly diminish their fire structural integrity when loaded in compression. Basalt laminates have a higher absorptivity than glass composites, causing them 
to heat-up more rapidly and reach higher temperatures. This accelerates thermal softening of the laminate and also leads to inferior fire reaction properties, including shorter ignition times, higher heat release rates, faster decomposition and thicker smoke. The faster heating rate experienced by the basalt laminate causes it to laterally deflect more rapidly and by a greater amount due to the greater thermal moments induced by the steep through-thickness temperature gradient. The fire structural integrity of both the basalt and glass laminates decrease with increasing applied compressive stress and heat flux. However, the structural integrity of the basalt laminate is inferior due to its higher absorptivity.

\section{ACKNOWLEDGEMENTS}

This work was undertaken as part of the Composites Fire Performance project of the Cooperative Research Centre for Advanced Composite Structures Ltd (CRC-ACS), established and supported under the Australian Government's Cooperative Research Centres Program. One of the authors (T.B.) thanks the CRC-ACS and RMIT University for the provision of a PhD scholarship. The authors thank Robert Ryan and Peter Tkatchyk from RMIT University for technical assistance in the manufacture and testing of the composites, respectively.

\section{References}

1. Fiore V, Scalici T, Di Bella G, Valenza A. A review on basalt fibre and its composites. Comp B. 2015;74:74-94.

2. Dhand V, Mittal G, Rhee KY, Park S-J, Hui D. A short review on basalt fiber reinforced polymer composites. Comp B. 73:166-180.

3. Jamshaid H, Mishra R. A green material from rock: basalt fiber - a review. J Textile Inst. 2015:1-15.

4. Parnas R, Shaw M, Liu Q. Basalt fibre reinforced polymer composites. Fall River, MA: New England Transportation Consortium 2007.

5. Singha K. A short review on basalt fiber. Int J of Textile Sci. 2012;1:19-28.

6. Lipatov YV, Arkhangelsky IV, Dunaev AV, Gutnikov SI, Manylov MS, Lazoryak BI. Crystallization of zirconia doped basalt fibers. Thermo Acta 2014;575:238-243. 
7. Mingchao W, Zuoguang Z, Yubin L, Li M, Sun Z. Chemical durability and mechanical properties of alkali-proof basalt fiber and its reinforced epoxy composites. J Rein Plastics \& Comp. 2008;27:393-407.

8. Rybin VA, Utkin AV, Baklanova NI. Alkali resistance, microstructural and mechanical performance of zirconia-coated basalt fibers. Cement \& Concrete Res. 2013;53:1-8.

9. Scheffler C, Förster T, Mäder E, Heinrich G, Hempel S, Mechtcherine V. Aging of alkali-resistant glass and basalt fibers in alkaline solutions: Evaluation of the failure stress by Weibull distribution function. J Non-Cry Solids 2009;355:2588-2595.

10. Wei B, Cao H, Song S. Environmental resistance and mechanical performance of basalt and glass fibers. Mat Sci \& Eng A 2010;527:4708-4715.

11. Griffis CA, Nemes JA, Stonesifer FR, Chang CI. Degradation in strength of laminated composites subjected to intense heating and mechanical loading. J Comp Mat. 1986;20: 216-235.

12. Pering GA, Farrell PV, Springer GS. Degradation of tensile and shear properties of composites exposed to fire or high temperature. J Comp Mats. 1989;14:54-66.

13. Keller T, Tracy C, Hugi E. Fire endurance of loaded and liquid-cooled GFRP slabs for construction. Comp A. 2006;37:1055-1067.

14. L. Liu, G.A. Kardomateas, V. Birman, J.W. Holmes and G.J. Simitses, Thermal buckling of a heat exposed, axially restrained composite column, Comp A. 2006;37: 972-980.

15. Bausano JV, Lesko JJ, Case SW. Composite lifetime during combined compressive loading and one-sided simulated fire exposure: characterization and prediction, Comp A, 2006;37:1092-1100.

16. Boyd SE, Case SW, Lesko JJ. Compression creep rupture behavior of a glass/vinyl ester composite subject to isothermal and one-sided heat flux conditions. Comp A, 2007:38;1462-1472.

17. Gibson AG, Wu YS, Evans JT, Mouritz AP. Laminate theory analysis of composites under load in fire. J Comp Mat. 2006;40:639-658.

18. Feih S, Mathys Z, Gibson A.G, Mouritz A.P. Modelling the compression strength of polymer laminates in fire. Comp A. 2007;38:2354-2365.

19. Feih S, Mathys Z, Gibson AG, Mouritz AP. Modelling the tension and compression strengths of polymer laminates in fire. Comp Sci \& Tech. 2007;67:551-564.

20. Feih S, Mouritz AP, Mathys Z, Gibson AG. Tensile strength modelling of glass fiberpolymer composites in fire. J Comp Mat. 2007;41:2387-2410.

21. Mouritz AP, Gibson AG. Fire Properties of Polymer Composite Materials. The Netherlands: Springer Science \& Business Media, 2007.

22. Asaro RJ, Lattimer B, Ramroth W. Structural response of FRP composites during fire, Comp Struct. 2009;87:382-393.

23. Mouritz AP, Feih S, Kandare E, Mathys Z, Gibson AG, Des Jardin PE, Case SW, Lattimer BY. Review of fire structural modelling of polymer composites. Comp A. 2009;40:1800-1814.

24. Feih S, Mouritz AP. Tensile properties of carbon fibres and carbon fibre-polymer composites in fire. Comp A. 2012;43:765-772.

25. Bhat T, Chevali V, Liu X, Feih S, Mouritz AP. Fire structural resistance of basalt fibre composite. Comp A. 2015;71:107-115.

26. ISO 5660 - 1: 2015 Reaction-to-fire tests: Heat release, smoke production and mass loss rate - Part 1: Heat release rate (cone calorimeter method) and smoke production rate (dynamic measurement). 2015.

27. McGrattan K, Miles S. Modelling Fires Using Computational Fluid Dynamics (CFD). SFPE Handbook of Fire Protection Engineering. Spinger, 2016, pp. 1034-1065. 
28. Henderson JB, Wiebelt JA, Tant MR. A model for the thermal response of polymer composite materials with experimental verification. J Comp Mat. 1985;17:579-595.

29. Mouritz AP, Mathys Z, Gibson AG. Heat release of polymer composites in fire. Comp. 2006;37:1040-1054.

30. Liu L, Kardomateas GA, Birman V, Holmes JW, Simitses GJ. Thermal buckling of a heat-exposed, axially restrained composite column. Comp A. 2006;37:972-980. 
Table 1. Mechanical properties of the fibres and composites obtained experimentally.

\begin{tabular}{|l|c|c|}
\hline Property & Basalt Laminate & Glass Laminate \\
\hline Average fibre modulus $(\mathrm{GPa})$ & 72 & 76 \\
\hline Average fibre fracture stress $(\mathrm{MPa})$ & 2385 & 2261 \\
\hline Laminate tensile modulus $(\mathrm{GPa})$ & 23 & 25 \\
\hline Laminate tensile strength $(\mathrm{MPa})$ & 550 & 535 \\
\hline Laminate compressive modulus $(\mathrm{GPa})$ & 24.4 & 24.7 \\
\hline Laminate compressive strength $(\mathrm{MPa})$ & 198 & 255 \\
\hline
\end{tabular}

Table 2. Parameters used for the thermal model.

\begin{tabular}{|l|c|c|}
\hline Property & Basalt Laminate & Glass Laminate \\
\hline Fibre volume fraction $\left(\mathrm{V}_{\mathrm{f}}\right)$ & 0.51 & 0.55 \\
\hline Decomposition reaction constant, A (1/s) & $5.59 \times 10^{13}$ & $5.59 \times 10^{13}$ \\
\hline Activation energy, Q $(\mathrm{J} / \mathrm{kg} \mathrm{mol})$ & 212705 & 212705 \\
\hline Thermal conductivity $(\mathrm{W} / \mathrm{mK})\left(60-300^{\circ} \mathrm{C}\right)$ & 0.41 & 0.43 \\
\hline Remaining resin mass fraction $(\%)$ & 3.0 & 3.0 \\
\hline Absorptivity & 0.92 & 0.65 \\
\hline
\end{tabular}


Table 3. Fitted parameters used for the average strength and buckling models.

\begin{tabular}{|l|c|c|}
\hline Property & Basalt Laminate & Glass Laminate \\
\hline In-Plane compressive modulus, $\mathrm{E}_{\mathrm{c}(\mathrm{o})}(\mathrm{GPa})$ & 24.4 & 25.5 \\
\hline In-plane residual compressive modulus, $\mathrm{E}_{\mathrm{c}(\mathrm{R})}(\mathrm{GPa})$ & 9.5 & 9.5 \\
\hline Fitted mechanical glass transition temperature $\mathrm{T}_{\mathrm{kb}}\left({ }^{\circ} \mathrm{C}\right)$ & 106.2 & 103.6 \\
\hline Fitted value $\varphi_{\mathrm{b}}$ & 0.03 & 0.031 \\
\hline In-Plane compressive strength, $\sigma_{\mathrm{c}(\mathrm{o})}(\mathrm{MPa})$ & 196.2 & 255.4 \\
\hline In-Plane residual compressive strength $\sigma_{\mathrm{c}(\mathrm{R})}(\mathrm{MPa})$ & 8.24 & 8.55 \\
\hline Fitted mechanical glass transition temperature, $\mathrm{T}_{\mathrm{k}}\left({ }^{\circ} \mathrm{C}\right)$ & 94.0 & 100.2 \\
\hline Fitted Value $\varphi$ & 0.031 & 0.036 \\
\hline
\end{tabular}

Table 4. Fire reaction properties of the composites.

\begin{tabular}{|l|c|c|c|c|}
\hline Property & \multicolumn{2}{|c|}{$25 \mathrm{~kW} / \mathrm{m}^{2}$} & \multicolumn{2}{c|}{$50 \mathrm{~kW} / \mathrm{m}^{2}$} \\
\hline & $\begin{array}{c}\text { Basalt } \\
\text { Laminate }\end{array}$ & $\begin{array}{c}\text { Glass } \\
\text { Laminate }\end{array}$ & $\begin{array}{c}\text { Basalt } \\
\text { Laminate }\end{array}$ & $\begin{array}{c}\text { Glass } \\
\text { Laminate }\end{array}$ \\
\hline Peak heat release rate $\left(\mathrm{kW} / \mathrm{m}^{2}\right)$ & 18.2 & 4.2 & 247 & 176.5 \\
\hline Average heat release rate $\left(\mathrm{kW} / \mathrm{m}^{2}\right)$ & 6.3 & 2.6 & 156 & 96.9 \\
\hline Total heat release $\left(\mathrm{MJ} / \mathrm{m}^{2}\right)$ & 10.51 & 6.52 & 120.9 & 66.93 \\
\hline
\end{tabular}




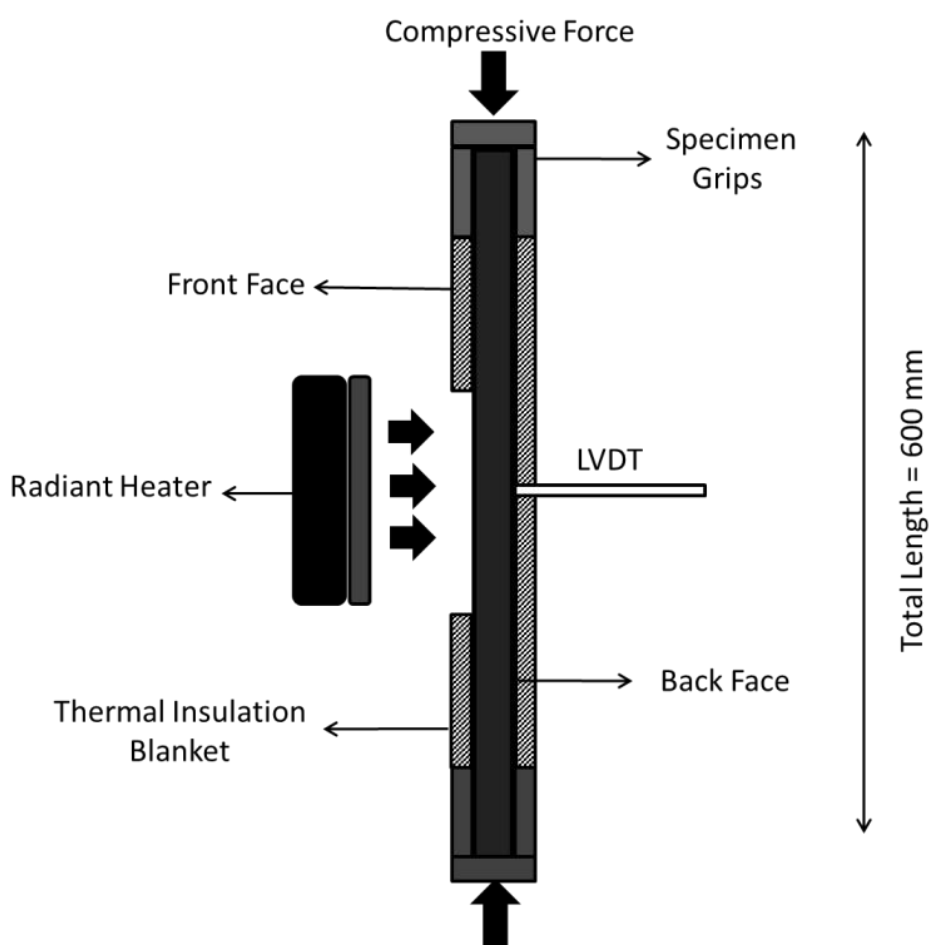

Figure 1. Schematic of the fire structural test. 


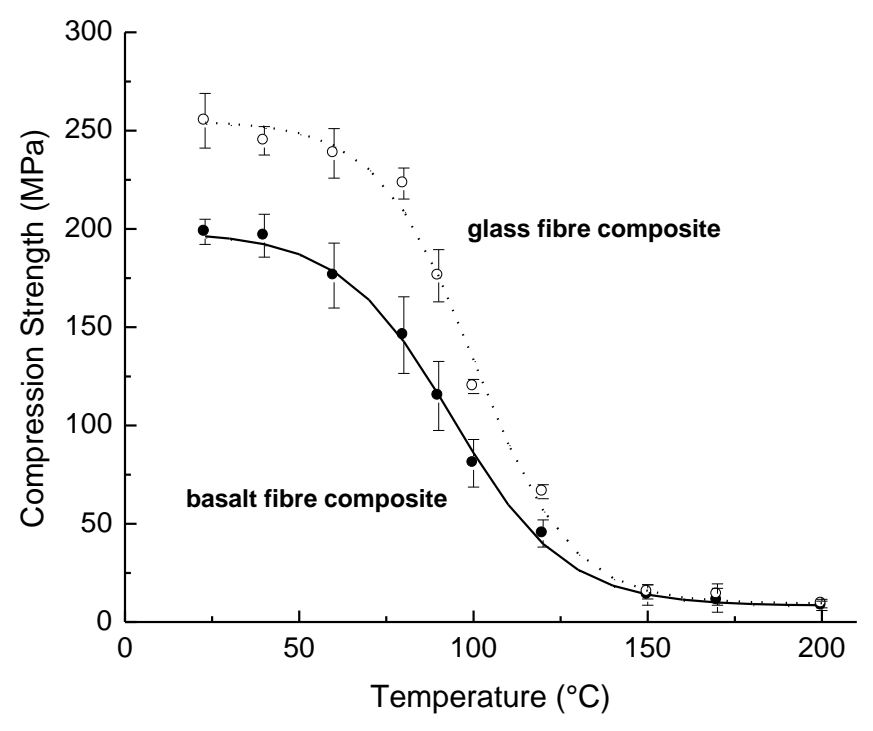

(a)

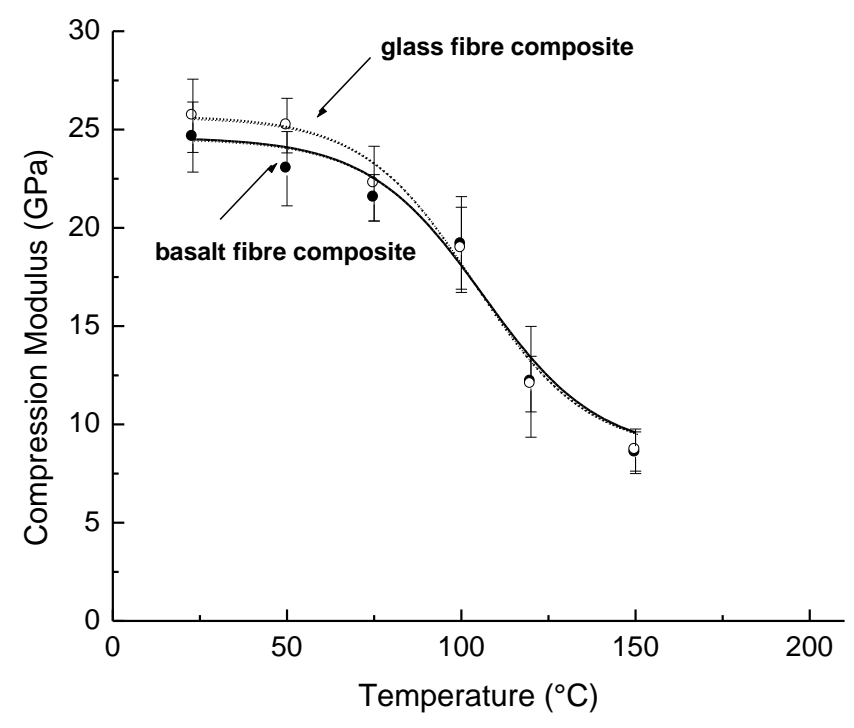

(b)

Figure 2. Effect of temperature on the compressive (a) failure stress and (b) Young's modulus of the basalt and glass laminates. The curves in (a) and (b) were calculated using Eqns. 4 and 7 , respectively. 


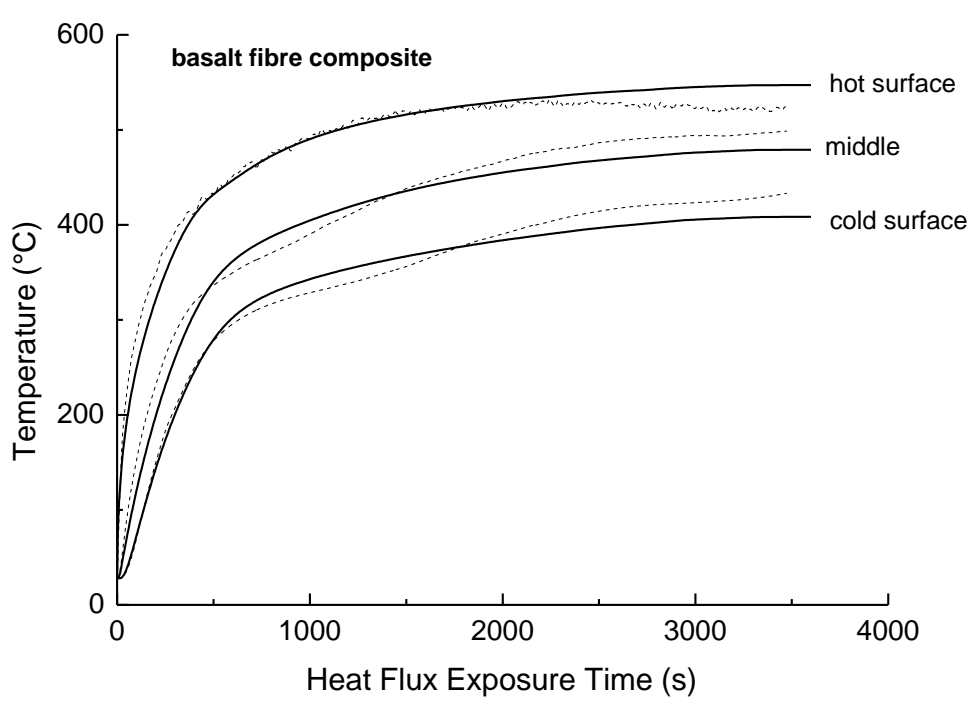

(a)

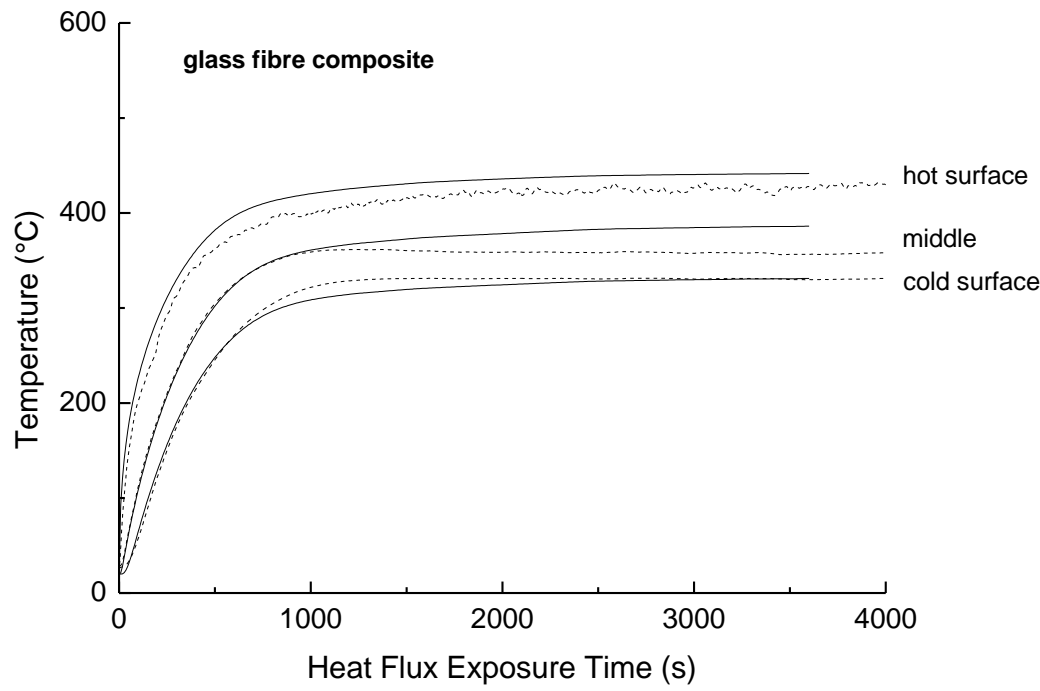

(b)

Figure 3. Temperature-time profiles for (a) basalt and (b) glass laminates at the heat flux of $25 \mathrm{~kW} / \mathrm{m}^{2}$. The dotted and solid curves indicate the measured and calculated temperatures, respectively. 


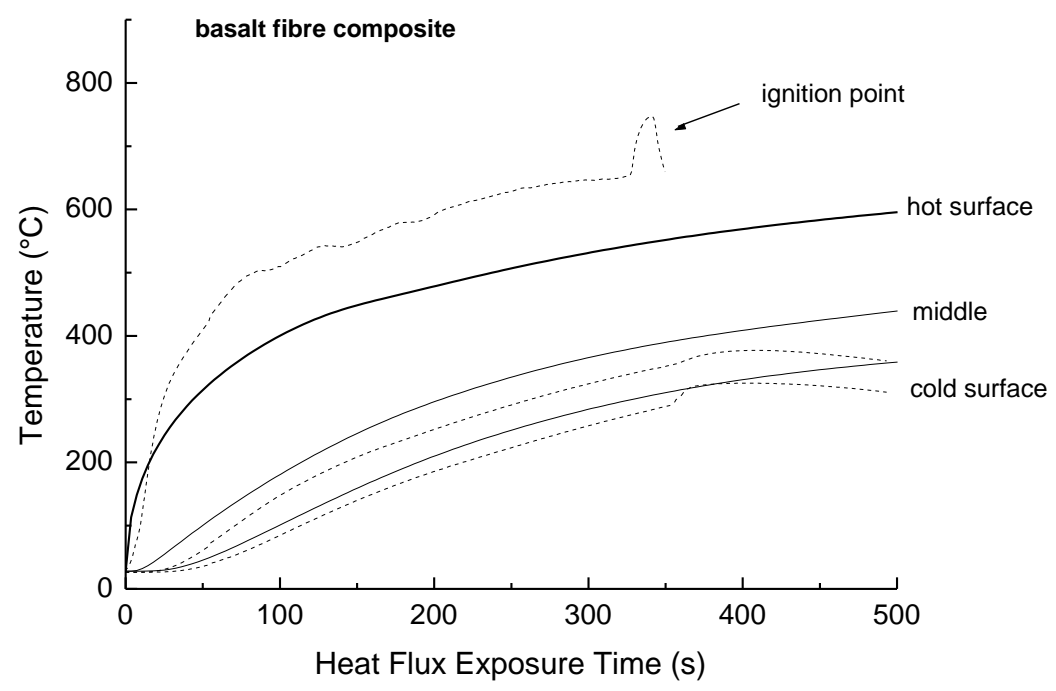

(a)

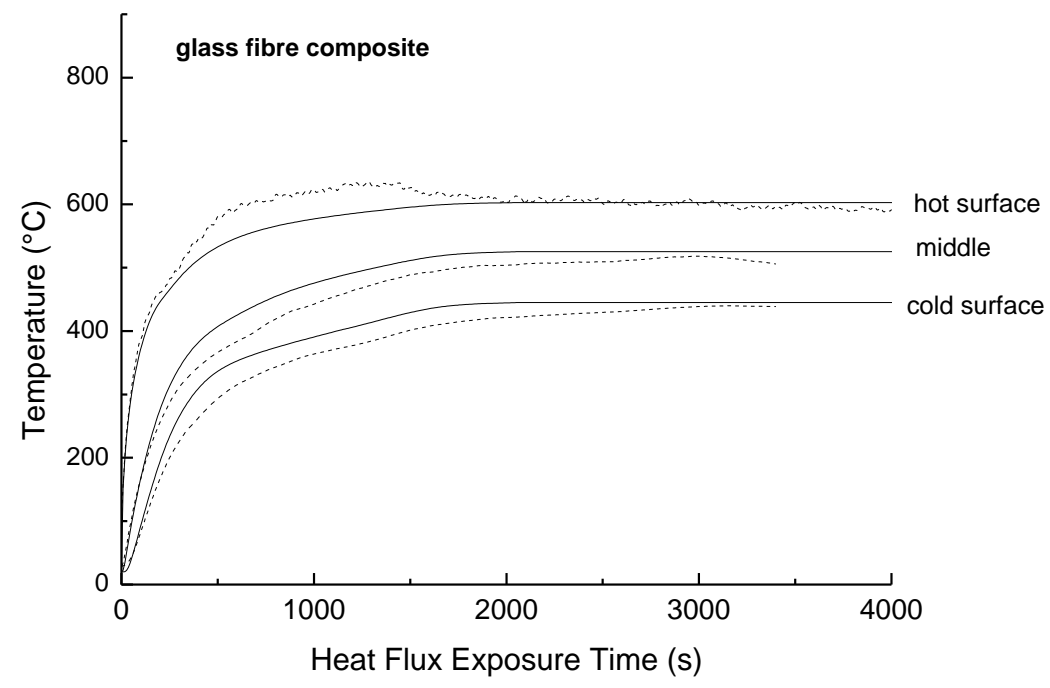

(b)

Figure 4. Temperature-time profiles for (a) basalt and (b) glass laminates at the heat flux of $50 \mathrm{~kW} / \mathrm{m}^{2}$. The dotted and solid curves indicate the measured and calculated temperatures, respectively. 


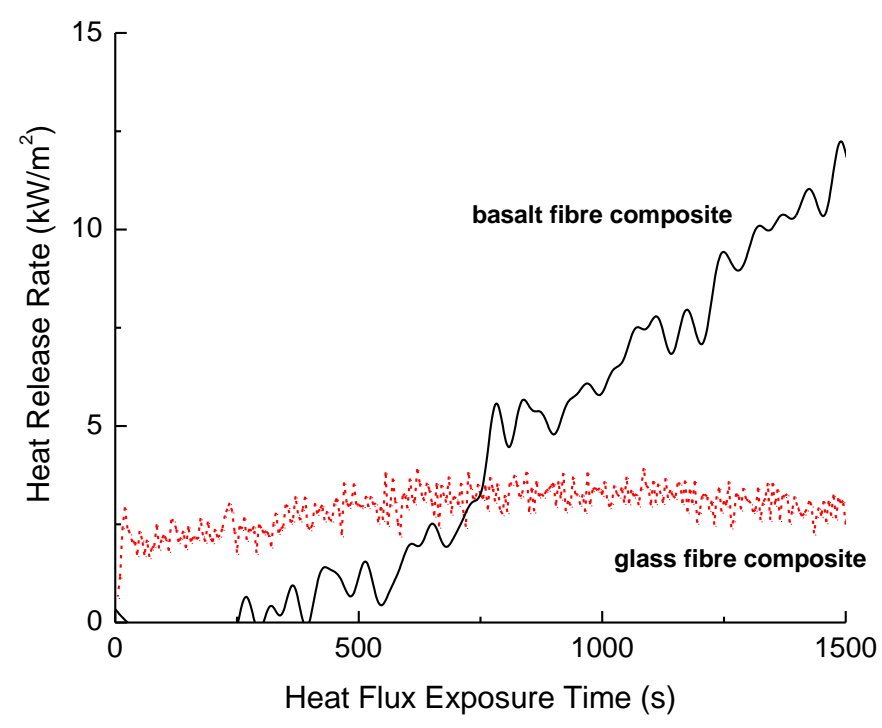

(a)

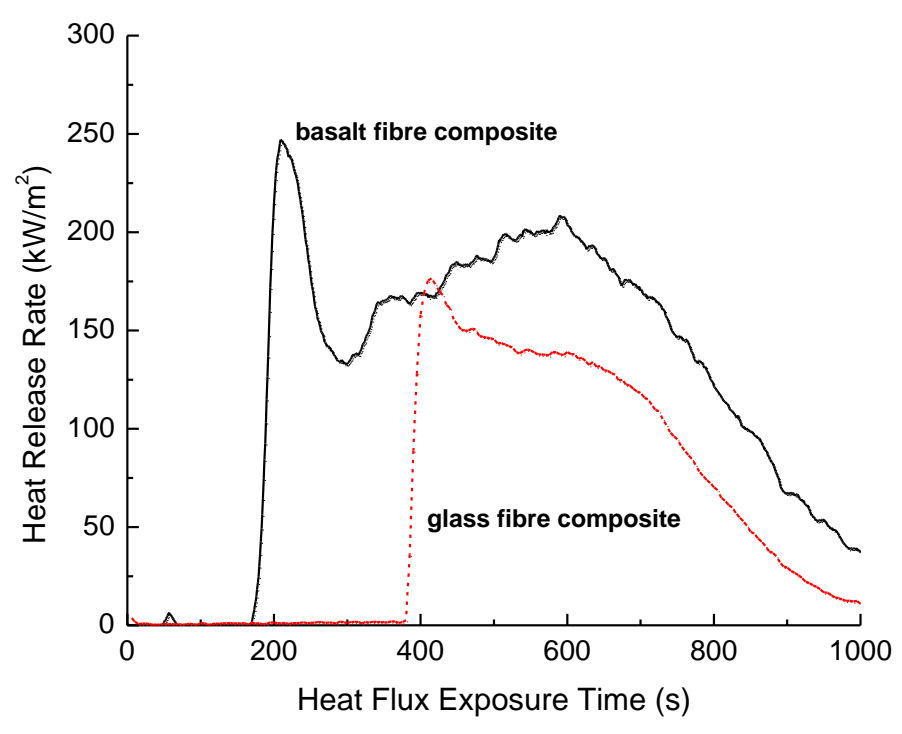

(b)

Figure 5. Effect of increasing exposure time on the heat release rate of the laminates at the heat flux of (a) $25 \mathrm{~kW} / \mathrm{m}^{2}$ and (b) $50 \mathrm{~kW} / \mathrm{m}^{2}$. 


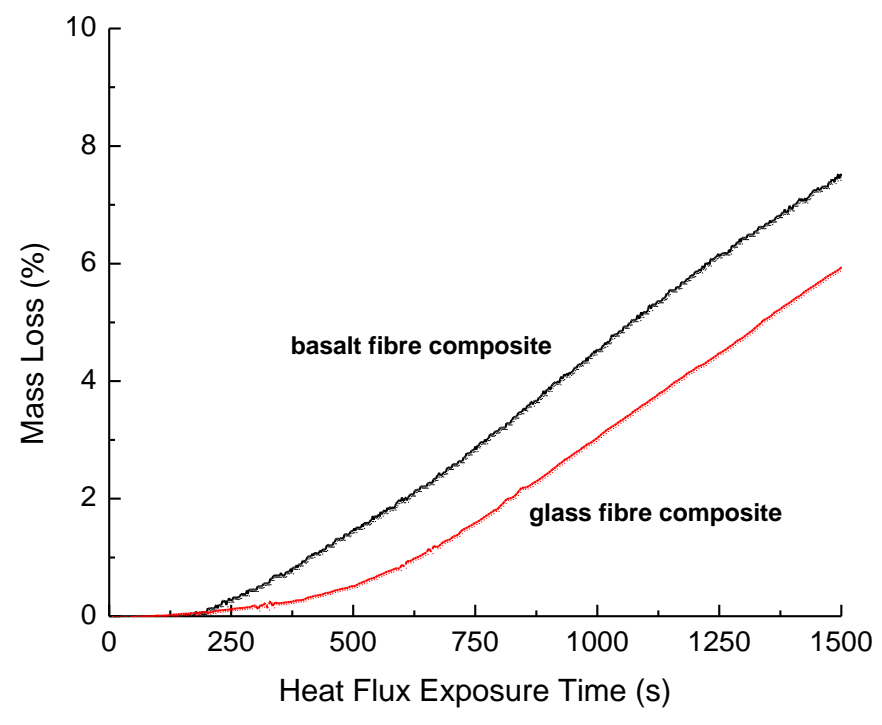

(a)

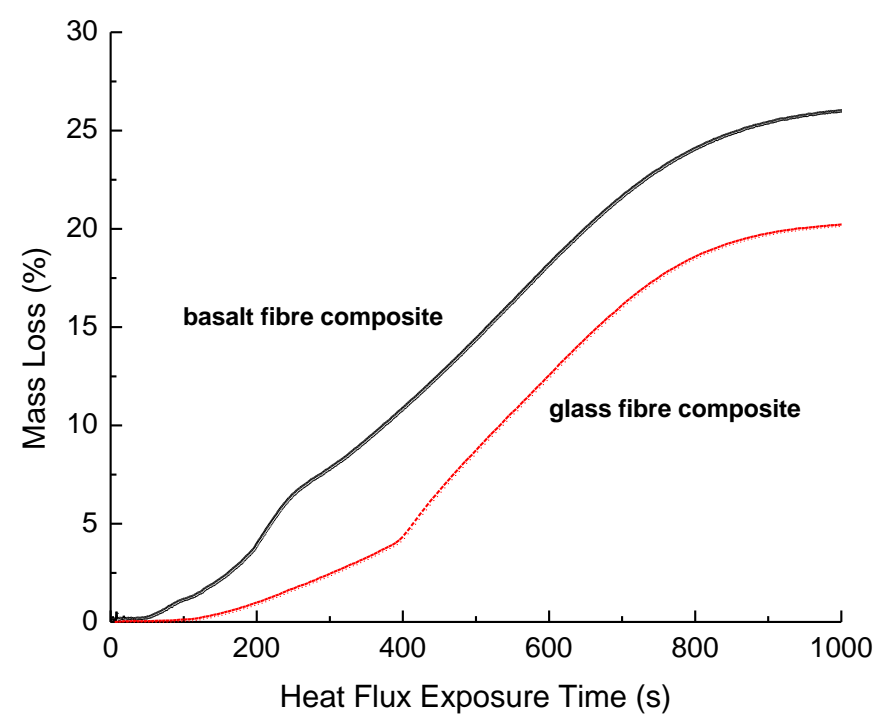

(b)

Figure 6. Effect of increasing exposure time on the mass loss of the laminates at the heat flux of (a) $25 \mathrm{~kW} / \mathrm{m}^{2}$ and (b) $50 \mathrm{~kW} / \mathrm{m}^{2}$. 


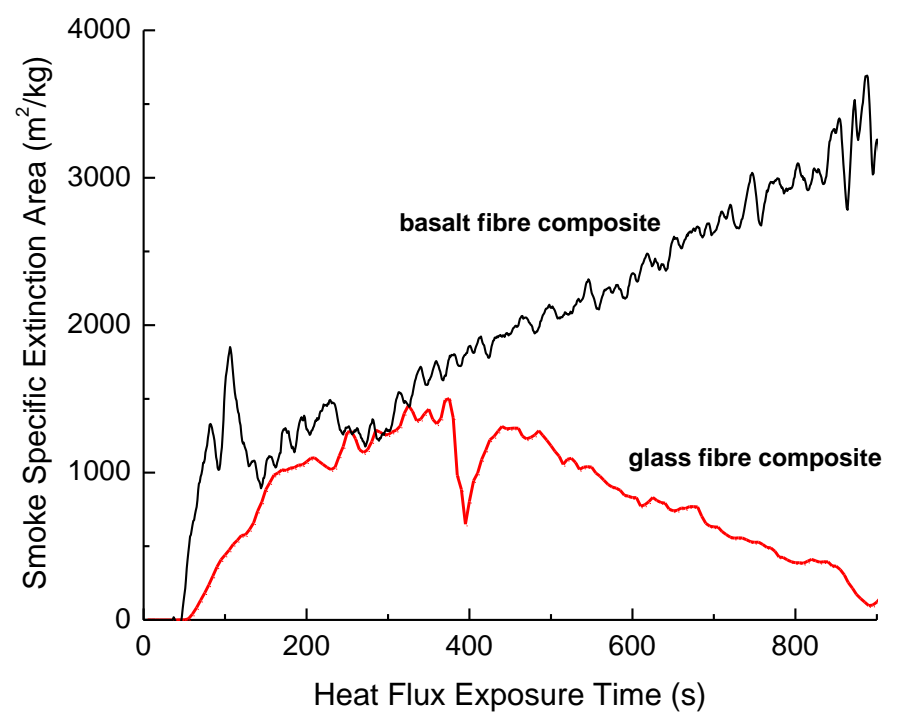

Figure 7. Effect of increasing exposure time on the smoke specific extinction area for the basalt and glass laminates at the heat flux of $50 \mathrm{~kW} / \mathrm{m}^{2}$.

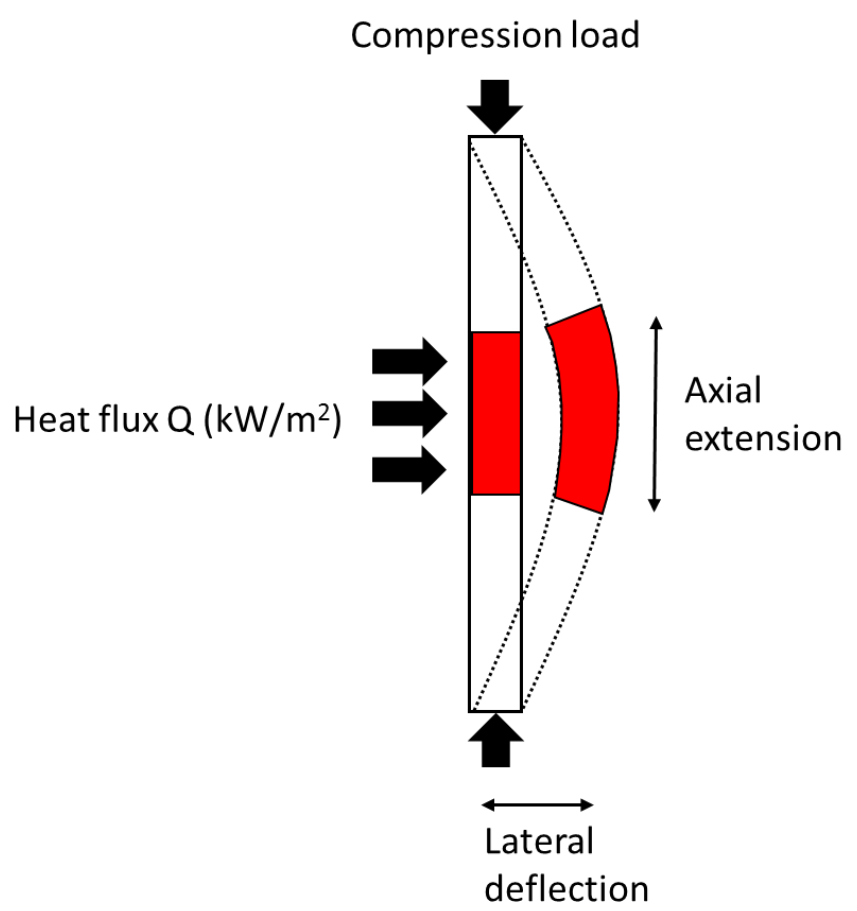

Figure 8. Schematic of the axial extension and lateral deflection of a laminate beam subjected to combined compression loading and one-sided heating. 


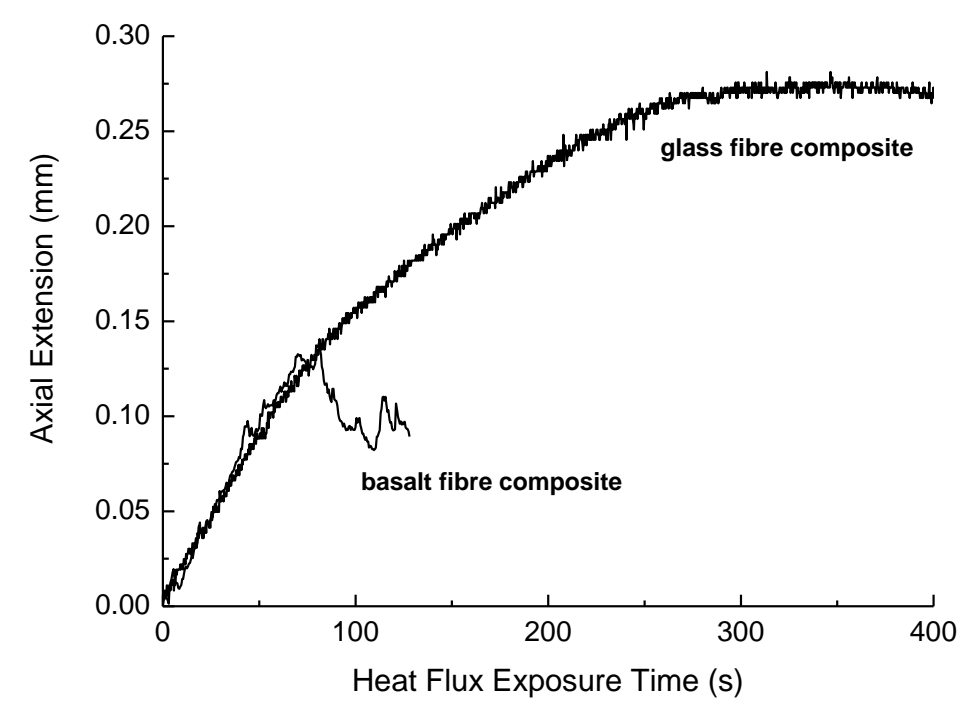

(a)

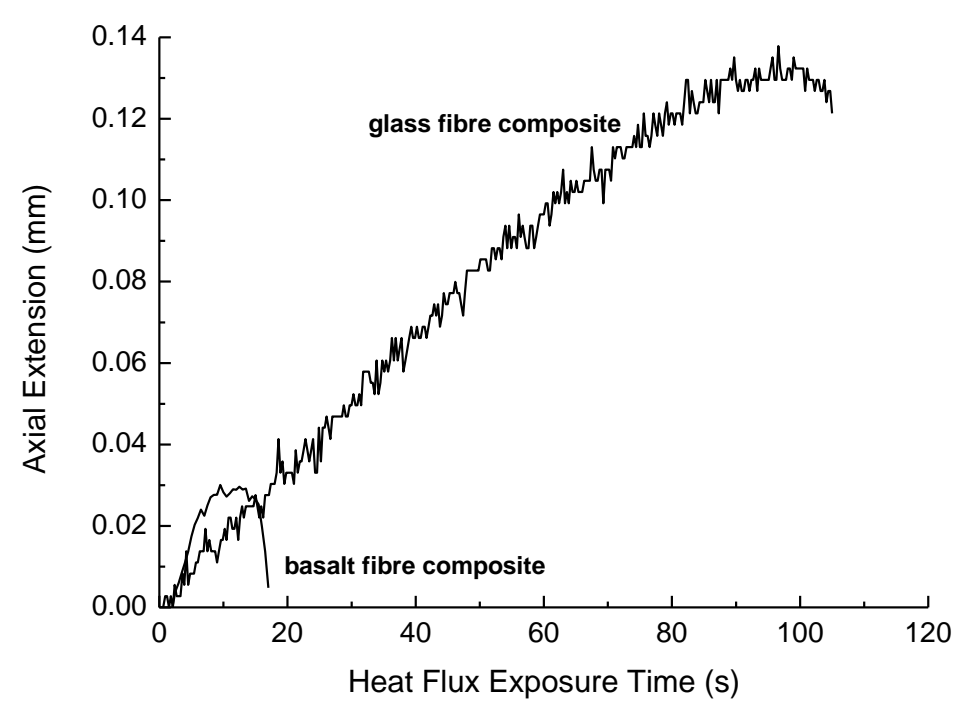

(b)

Figure 9. In-plane extension of basalt and glass laminates loaded to (a) $20 \%$ and (b) $80 \%$ of the room temperature Euler buckling force and exposed to the heat flux of $50 \mathrm{~kW} / \mathrm{m}^{2}$. 


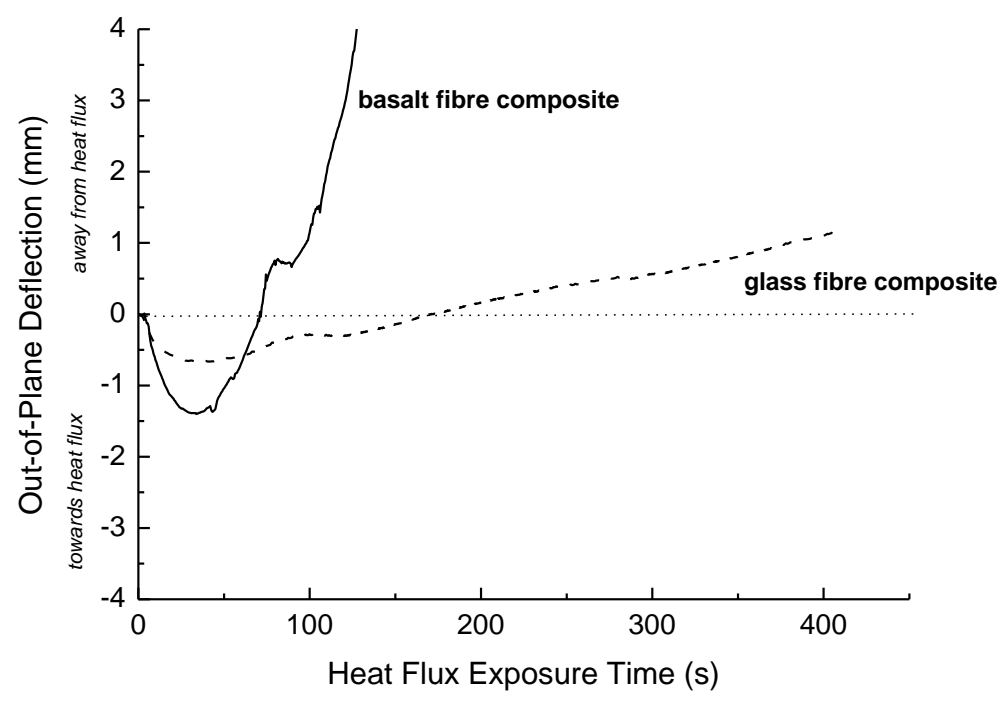

(a)

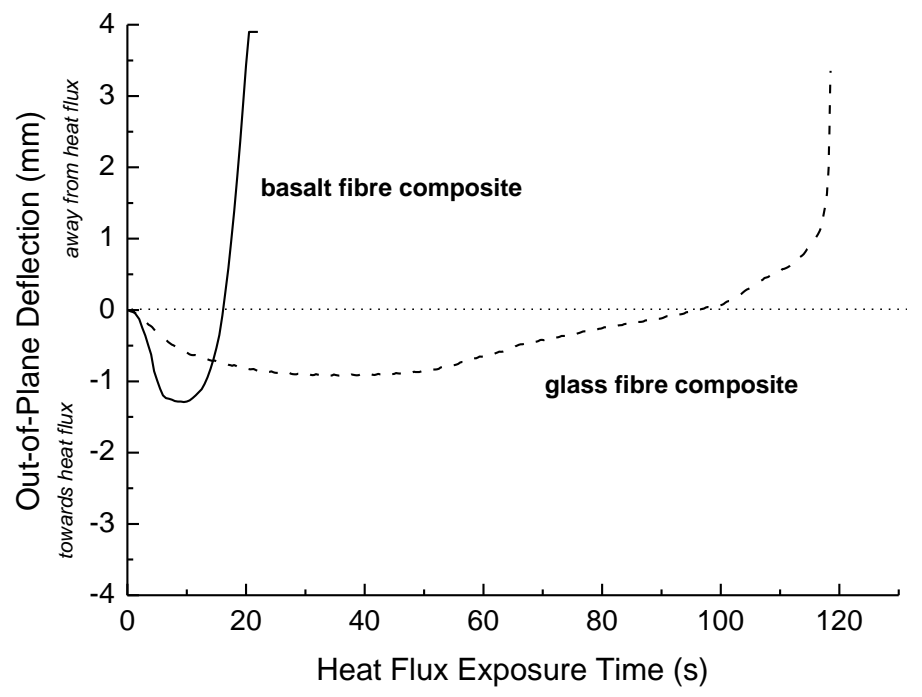

(b)

Figure 10. Out-of-plane deflection of basalt and glass laminates loaded to (a) $20 \%$ and (b) $80 \%$ of the room temperature Euler buckling force and exposed to the heat flux of $50 \mathrm{~kW} / \mathrm{m}^{2}$. 


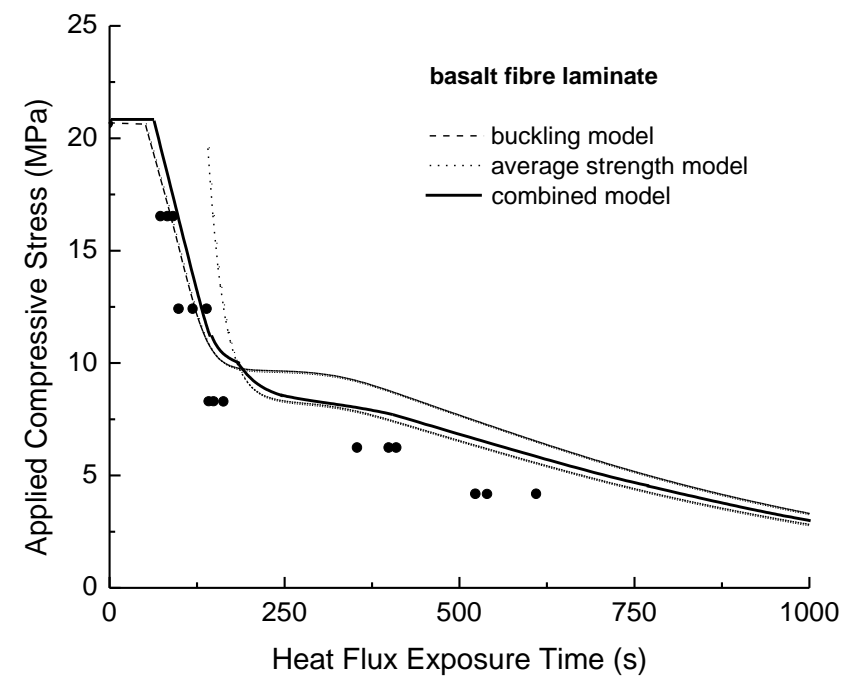

(a)

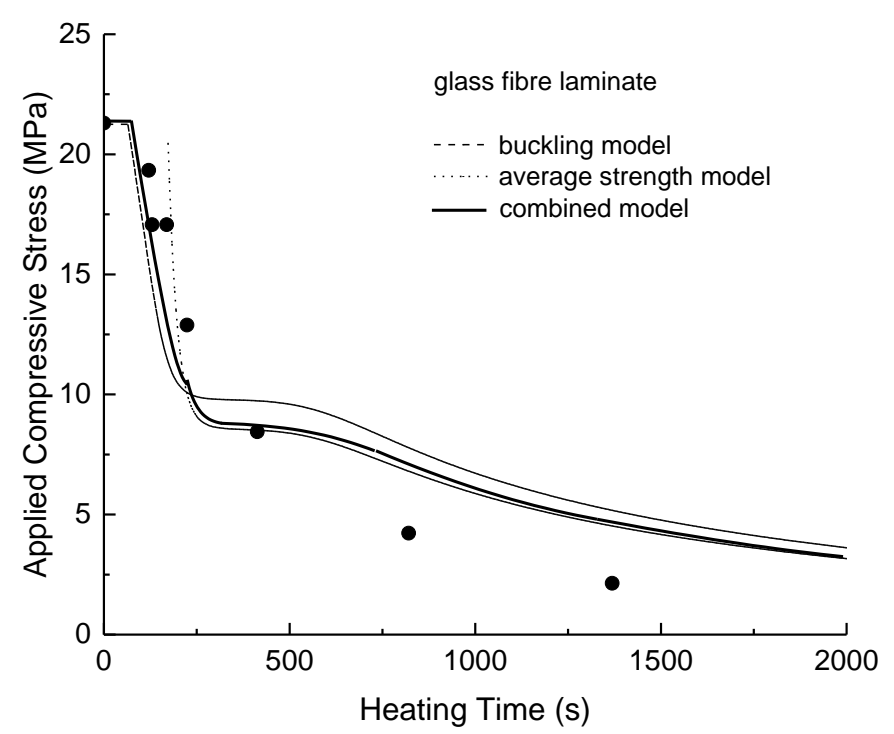

(b)

Figure 11. Effect of applied stress on failure times of (a) basalt and (b) glass laminates when exposed to the heat flux of $25 \mathrm{~kW} / \mathrm{m}^{2}$. 


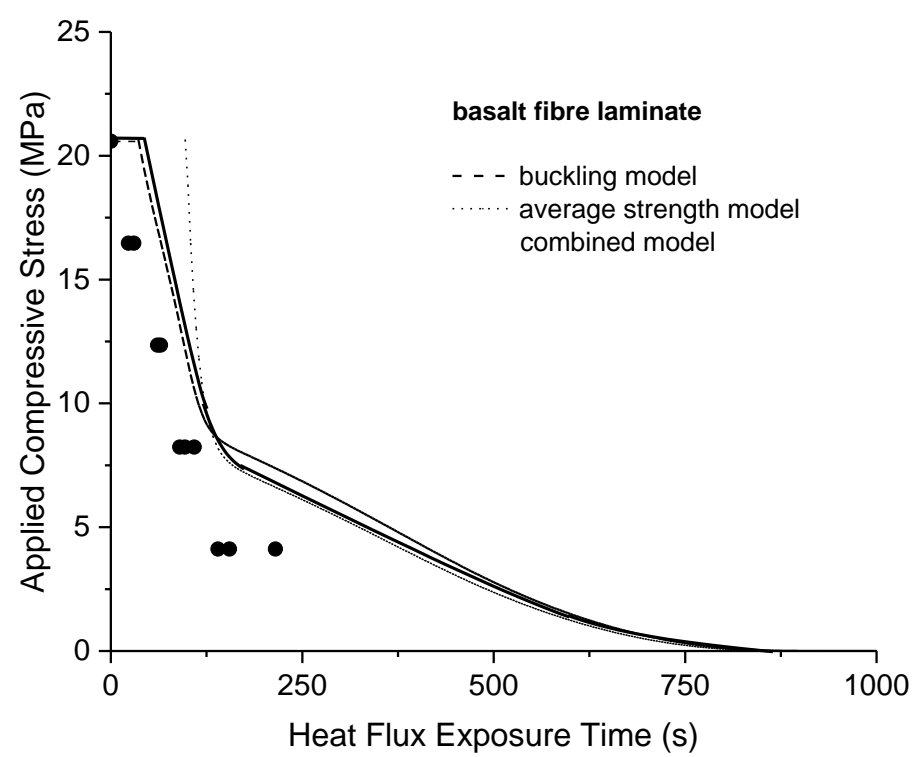

(a)

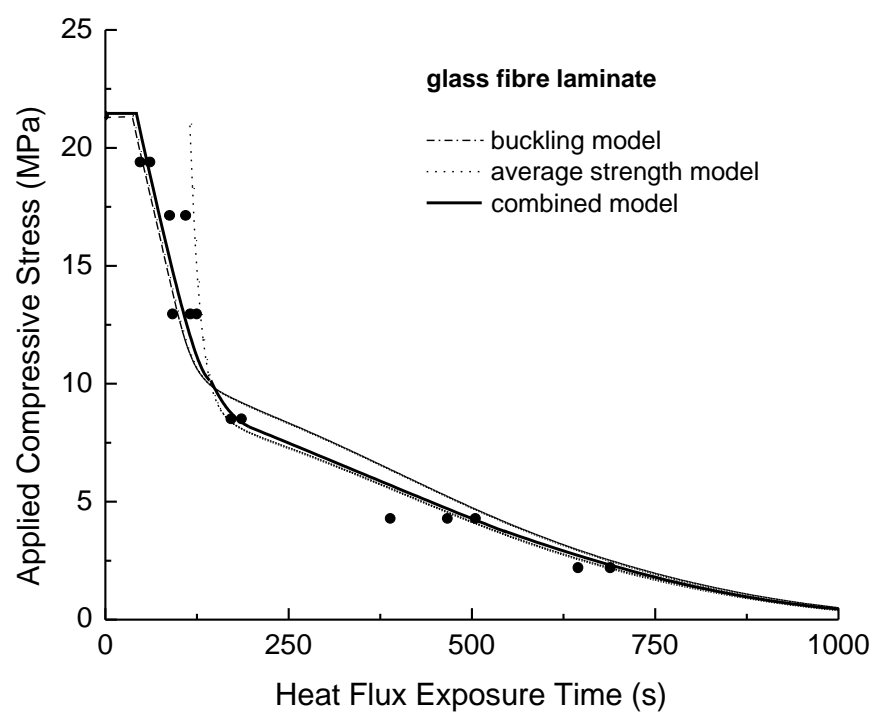

(b)

Figure 12. Effect of applied stress on failure times of (a) basalt and (b) glass laminates when exposed to the heat flux $50 \mathrm{~kW} / \mathrm{m}^{2}$. 


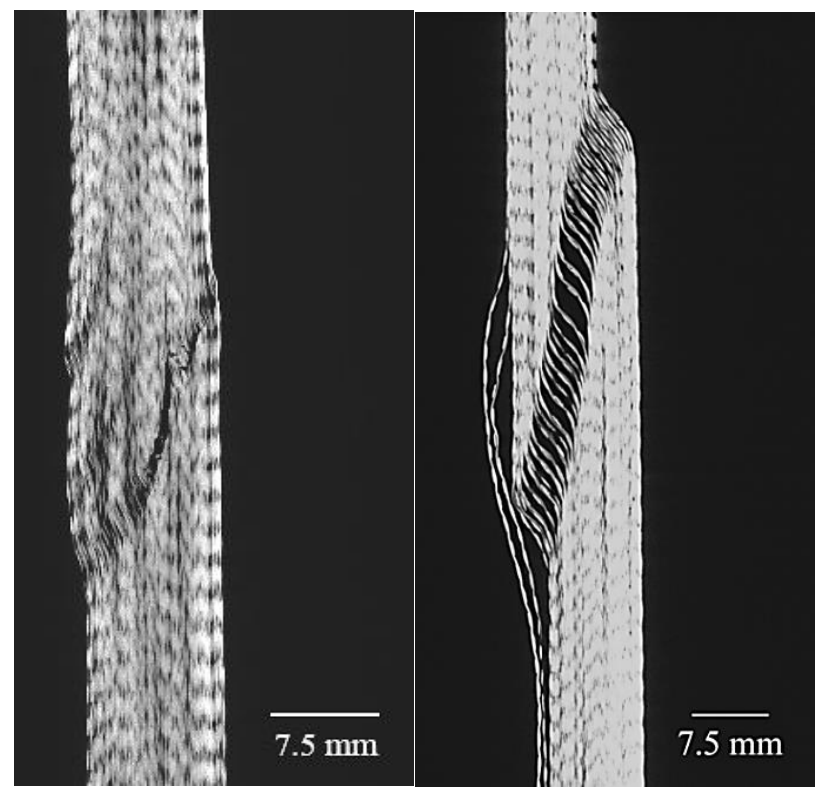

(a)

(b)

Figure 13. X-ray computed tomography images of compressive failure of the basalt laminate loaded to (a) $80 \%$ and (b) $20 \%$ of the room temperature Euler buckling load and exposed to the heat flux. 